\title{
UM OLHAR SOBRE A EDUCAÇÃO AMBIENTAL NAS INSTITUIÇÕES DE ENSINO SUPERIOR
}

Agessander Manoel ${ }^{1}$, Geovana de Oliveira Pereira ${ }^{2}$, Isaque Ferreira Alves da Silva ${ }^{3}$

${ }^{1}$ Universidade do Oeste Paulista - UNOESTE, Curso de Administração, ${ }^{2}$ Curso Superior Tecnológico em Gestão Comercial, ${ }^{3}$ Curso de Psicologia, Presidente Prudente, SP. E-mail: agessandermanoel@hotmail.com

\section{RESUMO}

O presente trabalho aborda a temática da educação socioambiental ao confrontar a Lei de Educação Ambiental com a formação nas Instituições de Ensino Superior. O objetivo deste estudo foi apresentar como está contextualizada a Educação Ambiental nas Instituições de Ensino Superior. A metodologia constou da técnica de pesquisas bibliográficas visando abordar, conhecer, discutir e reforçar análises de pesquisas científicas bem como permitir novas discussões. Os resultados caracterizaram a importância do ensino da Educação Ambiental, como estratégia de resolução para as problemáticas ambientais existentes. A conclusão mostra que o ensino correto da Educação Ambiental nas Instituições de Ensino Superior representa uma emergente necessidade no contexto socioeconômico e ambiental, além de uma oportunidade de agregar aos cursos e aos graduandos um diferencial competitivo.

Palavras-chave: Educação Ambiental, Instituições de Ensino Superior, Resíduos Sólidos, Lei 9.795/99, Formação.

\section{A LOOK ON ENVIRONMENTAL EDUCATION IN HIGHER EDUCATION INSTITUTIONS}

\begin{abstract}
This paper addresses the issue of environmental education to confront the Environmental Education Act with training in higher education institutions. The aim of this study was to present as is contextualized environmental education in higher education institutions. The methodology consisted of bibliographic research technique aimed at addressing, meet, discuss and strengthen scientific research analyzes and allow new discussions. The results marked the importance of teaching environmental education as solving strategy for existing environmental problems. The conclusion shows that the correct teaching of environmental education in higher education institutions is an emerging need in the socioeconomic and environmental context, as well as an opportunity to add to the courses and graduate students a competitive edge.
\end{abstract}

Keywords: Environmental Education, Higher Education Institutions, Solid Waste, Law 9.795 / 99, Formation. 


\section{INTRODUÇÃO}

A atual globalização, o crescimento econômico e a evolução da tecnologia vêm mudando de forma intensa e acelerada, o cenário mundial. Estas mudanças abrangem todos os setores sociais e suas formas de interagir. $\mathrm{O}$ ensino, embora pouco discutido nos cenários políticos e de mídia, é a base que sustenta toda mudança. Segundo Godecke, Naime e Figueiredo (2012) o aumento da população e sua concentração em áreas urbanizadas têm ampliado a utilização dos serviços ecossistêmicos levando a uma depleção seja pela produção e consumo como pelo resultado de seus descartes e resíduos.

Tornou-se assim necessário um pensar na reeducação no modo de ver e agir perante as questões ambientais. No Brasil esta reeducação foi proposta através da Educação Ambiental e instituída por meio da Lei 9.795/99, que se tornou a base da resolução № 2, de 15 de junho de 2012 que estabelece as Diretrizes Curriculares Nacionais para a Educação Ambiental. Adams (2012, p. 2148) pondera que:

Sem o conhecimento destes documentos e de outros importantes documentos referência, a Educação Ambiental continuará a ser trabalhada de forma estanque, fragmentada, limitada a comemorações de datas como Dia da Água, Dia da Terra, Dia do Índio, Dia do Meio Ambiente, e limitada a temas como a separação do lixo, desastres ambientais e temáticas catastróficas, - que mais assustam do que educam - para o despertar de uma consciência ambiental.

Para Nascimento (2014) as universidades devem atender as exigências legais que as regem, bem como satisfazer os seus alunos, que ocupam a posição de clientes, enfrentando assim, o desafio de desenvolver novas grades curriculares que despertem a consciência ambiental de uma forma atrativa para os seus consumidores.

Segundo Kotler e Fox (1994, p. 48) "a competitividade em qualquer setor que seja, leva as instituições a buscarem a melhoria continua de seus serviços e processos, na área educacional, observa-se que as melhorias têm o propósito de manter e atrair novos clientes." Assim, o presente trabalho tem como objeto a temática da Educação Ambiental e por objetivo, apresentar como a mesma encontra-se contextualizada nas Instituições de Ensino Superior.

\section{METODOLOGIA}

Segundo Mascarenhas (2012, p. 36) "Em geral, chamamos de método o conjunto de técnicas que usamos em um estudo para obter uma resposta", ou seja, é o caminho que utilizamos para atingir a conclusão científica. A pesquisa de acordo com Marconi e Lakatos (2010, p. 44) "é um procedimento formal, com método de pensamento reflexivo, que requer um tratamento científico e se constitui no caminho para conhecer a realidade ou descobrir verdades parciais."

A técnica utilizada neste trabalho é a pesquisa bibliográfica, pois segundo Manzo (apud MARCONI E LAKATOS, 2010, p.166), "oferece meios para definir, resolver, não somente problemas já conhecidos, como também explorar novas áreas onde os problemas não se cristalizaram suficientemente" e tem por objetivo permitir ao pesquisador "o reforço paralelo na análise de suas pesquisas ou manipulação de suas informações" (TRUJILLO, apud MARCONI E LAKATOS, 2010,p. 166). A contribuição dos pesquisadores referenciados neste trabalho permitirá a discussão do tema proposto com bases científicas permitindo melhor compreensão do objeto estudado.

\section{RESULTADOS}

Diante da abrangência da temática da Educação Ambiental, identifica-se como uma das problemáticas o descarte incorreto de resíduos sólidos. Estes são definidos pela Lei nN 12.305 de 
2010, lei que institui a Política Nacional de Resíduos Sólidos, sendo que ela reconhece que os resíduos sólidos são originários das atividades domésticas, comerciais ou de limpeza de locais públicos, dentre outros serviços no espaço urbano. No Brasil o descarte correto de resíduos sólidos ainda é bastante precário, como mostra levantamento feito pela ABRELPE (Associação Brasileira de Empresas de Limpeza Pública e Resíduos Especiais), em 2014 foram coletados somente $90,6 \%$ dos resíduos sólidos dos 78,6 milhões aproximados que foram gerados, sendo que aproximadamente sete milhões de toneladas de "lixo" tiveram automaticamente uma destinação incorreta.

Esse número de descarte incorreto é ainda mais alarmante quando apresentado a quantidade de resíduos que foram coletados e não tiveram um descarte correto, representando $41,6 \%$, ou seja, quase 30 milhões de toneladas por ano. Sendo assim, $51 \%$ dos resíduos sólidos gerados no Brasil em 2014 tiveram o descarte incorreto. Assim, vemos a necessidade de implantar ferramentas estratégicas para gerir seu descarte correto e isso passa inevitavelmente pela Educação Ambiental, que é instituída no Brasil por meio da Lei 9.795/99.

Diante deste novo panorama legal as instituições de ensino superior passam a ter que se ajustar e oferecer diferenciais na formação de seus profissionais para destacar-se das concorrentes e, além de manter seus clientes já existentes, atrair novos. Tozzoni-Reis (2001, p. 34) pondera que nos cursos de graduação estão sendo formados "profissionais que atuarão direta ou indiretamente como educadores ambientais". Assim, a inserção da Educação Ambiental no ensino superior passa a ser uma necessidade eminente, como será discutido a seguir.

\section{DISCUSSÃO}

No que diz respeito à Educação Ambiental no Brasil, a ferramenta que melhor representa e que visa garantir sua efetividade é a Lei no 9.795/99, que dispõe sobre a Educação Ambiental, além de instituir a Política Nacional de Educação Ambiental. No artigo 10 desta Lei entende-se Educação Ambiental como "os processos por meio dos quais o individuo e a coletividade constrói valores sociais, conhecimentos, habilidades, atitudes e competências voltadas para a conservação do meio ambiente". Esta Lei coloca ainda que a Educação Ambiental seja parte essencial da educação nacional, entendendo que deve estar presente em todos os processos educativos, tanto na educação formal quanto não formal, mostrando assim preocupação do poder público em criar uma conscientização da população em relação a preservação do meio ambiente.

Em relação à educação formal uma das especificações da Lei é que a Educação Ambiental seja desenvolvida como uma prática educativa integrada, contínua e permanente em todos os níveis e modalidades do ensino formal e que a dimensão ambiental deve constar dos currículos e em todas as disciplinas. Assim estas duas especificações são critérios para a autorização de funcionamento das instituições de ensino e dos seus respectivos cursos, tanto na rede pública como privada.

Essa Lei, segundo Souza (2016) surge a partir de esforços de vários países, que realizaram inúmeras conferências para tratar sobre a Educação Ambiental, porém a que ficou historicamente marcada foi a Primeira Conferência Intergovernamental sobre Educação Ambiental realizada pela UNESCO, em Tbilisi, Georgia, Russia, de 14 a 26 de outubro de 1977. Dessa reunião surgiu a premissa de que a Educação Ambiental deveria ser multidisciplinar e integracionista. Foi criada então pela ONU na década de 1980 a Comissão Mundial sobre Meio Ambiente e Desenvolvimento. “Essa comissão encerrou seus trabalhos em 1987 e apresentou o seu relatório denominado Nosso Futuro Comum [...] cujo cerne é a proposição de medidas a serem tomadas pelos países para se promover o desenvolvimento sustentável" (BARBIERI, 2001 apud SOUZA, 2016, p. 1).

Foi realizada então em 1992 no Rio de Janeiro a Conferência sobre Desenvolvimento e Meio Ambiente, e se viu a necessidade de incorporar a Educação Ambiental "definitivamente como processo indispensável ao desenvolvimento sustentável, através da agenda de diretrizes 
para o século 21" (SOUZA, 2016, p. 2). Esses foram os pontos importantes que antecederam a instituição da Lei 9.795/99, porém sua efetividade ainda se mostra muito precária, já que ainda existe uma visão muito simplista e estanque do que seja a lei por parte dos educadores como apresenta Oliveira (2009, s/p apud ADAMS, 2012) "a temática ambiental está presente tanto no trabalho dos professores como no material didático, mas não é trabalhada interdisciplinarmente como determina a legislação de educação ambiental".

Neste sentido, a respeito da incorporação da Educação Ambiental pelas Instituições de Ensino Superior, parece não existir interesse direto em implementar a Educação Ambiental, e que quando adotam, o fazem pelo viés da gestão do meio ambiente, geralmente, em curto prazo, no qual, o ambiente é considerado como "um reservatório de recursos a serem explorados em função de um desenvolvimento" (SAUVÉ, 2005, p.320, apud THOMAZ E CAMARGO, 2013, p. 310).

Para Thomaz e Camargo (2013):

[...] as Instituições de Ensino Superior não têm efetivado mudanças nas estruturas curriculares e/ou institucionais com relação ao desenvolvimento da Educação Ambiental; que o desenvolvimento da Educação Ambiental no Ensino Superior, quando ocorre, é isolado, em geral em áreas biológicas; e que possíveis conteúdos sobre Educação Ambiental estão na dependência de profissionais capacitados para essa finalidade. (p. 315)

[...] é possível entender que as Instituições de Ensino Superior deixam em segundo plano as questões ambientais e principalmente o desenvolvimento da Educação Ambiental, diferentemente do que prescreve a legislação e, portanto, são levadas a desconsiderar subsídios para novas posturas curriculares advindos, por exemplo, dos seus Projetos Político-Pedagógicos. (p. 316)

Como pode ser visto existe pouco interesse por parte das Instituições de Ensino Superior em investir na Educação Ambiental, de modo que dê ao egresso uma formação critica preocupada com as questões ambientais. Sendo assim, o que se passará adiante pelos futuros educadores é uma Educação Ambiental conservadora.

Segundo Lima (2015), as atividades desenvolvidas pelos docentes que incluem a Educação Ambiental de modo conservador, abrangendo temas como água, lixo, entre outros, em datas comemorativas, sem o intuito de desenvolver uma perspectiva crítica que integre o currículo de modo interdisciplinar. Além disso, esta prática não acrescenta um conhecimento sobre a questão socioambiental, utilizando um discurso que não condiz com o que se propõe, produzindo ações isoladas que não desenvolvem a Educação Ambiental.

[...] o que percebe empiricamente é a existência de uma pseudo-ideologia sobre a necessidade de conservação do meio ambiente, porém ao confrontar com a gestão aplicada pouco se percebe de evolução já que a grande maioria das vezes recai ao senso comum. (JESUS E SILVA, 2016, p. 165)

Como forma de reforçar a legitimidade da Educação Ambiental foi homologada em 2012 as "Diretrizes Curriculares Nacionais da Educação Ambiental indicando que estas reconhecem a relevância e a obrigatoriedade da Educação Ambiental" (ADAMS, 2012, p. 2151). As Diretrizes 
Curriculares Nacionais para a Educação Ambiental afirmam que:

A Educação Ambiental é uma dimensão da educação, é atividade intencional da prática social, que deve imprimir ao desenvolvimento individual um caráter social em sua relação com a natureza e com os outros seres humanos, visando potencializar essa atividade humana com a finalidade de torná-la plena de prática social e de ética ambiental. (RESOLUÇÃO № 2, DE 15 DE JUNHO DE 2012)

Tomando este conceito como base de uma proposta pedagógica Pedro (2010, p. 56) afirma que:

[...] a elaboração de uma proposta pedagógica deve ser construída considerando dois aspectos: o primeiro está relacionado à legislação, às diretrizes nacionais, normas, regulamentações e orientações curriculares e metodológicas advindas dos diferentes níveis do sistema educacional (LDB, Diretrizes Curriculares Nacionais Gerais, Catálogo Nacional de Cursos Superiores de Tecnologia, etc.); o segundo, está diretamente ligado às práticas e às necessidades dos diferentes sujeitos da instituição educativa (docentes, alunos, coordenadores, comunidade, etc.).

Jesus e Silva (2016) defendem a idéia de que nas universidades a Educação Ambiental deve ser incluída em todos os cursos, para a formação curricular dos estudantes, mas não como disciplina específica e sim abordando as questões ambientais de forma mais ampla, trocando experiências e idéias para diminuir o impacto causado sobre o meio ambiente.

Porém como salienta Velasco (2002, apud THOMAZ E CAMARGO, 2013, p. 310) é:

[...] preferível ter ao menos um espaço garantido para a Educação Ambiental na forma de disciplina do que não termos nada em absoluto, além de observar que não ofertar conteúdos disciplinares relacionados à Educação Ambiental, na graduação, pode ser interpretado como a perda de espaços de reflexão que implica impossibilidade de novas propostas pedagógicas.

Estas discussões fortalecem o pensamento da necessidade de inserir a temática ambiental nas Instituições de Ensino Superior, buscando desenvolver a educação de maneira inovadora e crítico-reflexivo na formação de profissionais comprometidos com a responsabilidade social e ambiental. Durante o curso de ensino superior o aluno deve ser preparado para estar à frente de desafios diversos, inclusive na questão ambiental.

\section{CONCLUSÃO}

A discussão provocada pelos autores reforça o intuito da Lei 9.795/99, como obrigatoriedade de incorporar a temática ambiental no processo de formação no ensino superior. Esta adequação deve ser verificada e aplicada como uma necessidade legal, social e mercadológica por induzir a um diferencial competitivo tanto para a instituição como para seus egressos.

Em sua abrangência a Educação Ambiental deve caracterizar um diferencial na formação profissional e de cidadania do aluno universitário, de maneira que o mesmo perceba-a como uma necessidade para si, para a sociedade e para o meio ambiente. Abordagens ambientais e ações limitadas ou esporádicas não permitem assegurar o desenvolvimento e a formação de conhecimento, valores habilidades, competência e atitudes que formem profissionais preparados e com conhecimento interdisciplinar suficiente para ação e disseminação das práticas ambientais. 


\section{REFERÊNCIAS}

BRASIL. Lei n. 9795, de 27 de abril de 1999. Dispõe sobre a educação ambiental. Política Nacional de Educação Ambiental. Brasília, DF, $1999 . \quad$ Disponível em:<http://www.planalto.gov.br/ccivil 03/leis/L9795.htm>. Acesso em: 04 de julho de 2016.

BRASIL. Lei n.o 12.305, de 02 de agosto de 2010. Esta Lei institui a Política Nacional de Resíduos Sólidos, dispondo sobre seus princípios, objetivos e instrumentos, bem como sobre as diretrizes relativas à gestão integrada e ao gerenciamento de resíduos sólidos, incluída os perigosos, às responsabilidades dos geradores e do poder público e aos instrumentos econômicos aplicáveis. Diário Oficial [da] República Federativa do Brasil, Brasília, DF, 3 ago 2010. Disponível em: <http://www.planalto.gov.br/ccivil 03/ ato2007-2010/2010/lei/l12305.htm>.Acesso em: 06 dejulho de2016

BRASIL. RESOLUÇÃO № 2, DE 15 DE JUNHO DE 2012. Estabelece as Diretrizes Curriculares Nacionais para a Educação Ambiental. DOU no 116, Seção 1, págs. 70-71 de 18/06/2012.

ABRELPE. Panorama de resíduos Sólidos no Brasil em 2014. Disponível em:<http://www.abrelpe.org.br/Panorama/panorama2014.pdf> Acesso em: 06 julho de 2016. Instituto Brasileiro do Meio Ambiente. Disponível em: <http://www.ibama.gov.br/areastematicas/projeto-educacao-ambiental >. Acesso em: 03 de julho de 2016.

ADAMS, Berenice Gehlen. A Importância da Lei 9.795/99 e das Diretrizes Curriculares Nacionais da Educação Ambiental para Docentes, Monografias Ambientais, v(10), no 10, p. 2148 - 2157, OUT DEZ 2012. Disponível em: <http://periodicos.ufsm.br/remoa/article/view/6926>. Acesso em: 20 de julho e 2016.

GODECKE, M. V.; NAIME, R.H.; FIGUEIREDO, J. A. S.; O consumismo e a Geração de Resíduos Sólidos Urbanos no Brasil. Rev. Elet. em Gestão, Educação e Tecnologia Ambiental, v(8), no 8, p.

1700-1712, SET-DEZ, 2012.Disponível em: <http://periodicos.ufsm.br/reget/article/view/6380>. Acesso em: 20 de julho de 2016.

JESUS, Djanires Lageano Neto de. SILVA, Roberta de Arruda Braga. A INCLUSÃO DA EDUCAÇÃO AMBIENTAL NOS CONTEÚDOS CURRICULARES DO ENSINO SUPERIOR SUL-MATOGROSSENSE: CENÁRIOS E PERSPECTIVAS. Revbea - Revista brasileira de educação ambiental. São Paulo, V.11, No 2: 164-177, 2016.2 Disponível em: <http://www.sbecotur.org.br/revbea/index.php/revbea/article/view/4538>. Acesso em: 09 de Agosto de 2016.

KOTLER, P.; FOX K.F.A. Marketing estratégico para instituições educacionais. São Paulo: Atlas, 1994.

LIMA, Gleice Prado. Educação ambiental crítica: da concepção à prática. Revista Servipana de Educação Ambiental.v. 1, n. 2, $2015 . \quad$ Disponível em: <http://www.seer.ufs.br/index.php/revisea/article/view/4443>. Acesso em: 09 de agosto de 2016.

MARCONI, M. A.; LAKATOS, E. M.Fundamentos de Metodologia Científica. 7. ed. São Paulo: Atlas, 2010. 
MASCARENHAS, S. A. Metodologia Científica. 1. ed. São Paulo: Pearson Education do Brasil, 2012. Disponível

em:<http://unoeste.bv3.digitalpages.com.br/users/publications/9788564574595/pages/-12>.

Acesso em: 13 de julho de 2016.

NASCIMENTO, N. M.; Qualidade na prestação de serviço: Uma análise no setor de ensino. Lisboa, 2014.

Disponível

em:<https://comum.rcaap.pt/bitstream/10400.26/10829/1/DISSERTAu00C7u00C30\%20Nadja\%20

-\%20Finalizada.pdf>. Acesso em: 20 de julho de 2016.

PEDRO, J. G. Curso Superior de Tecnologia em Gestão Comercial: Uma análise da formação superior tecnológica. 2010.2 Disponível em: $<$ http://tede.unoeste.br/tede/tde busca/arquivo.php?codArquivo=224>. Acesso em: 03 de julho de 2016.

SOUZA, Maria de Fátima de. Educação Ambiental: Como surgiu e a que se destina. 2016.Disponível em:<https://www.academia.edu/8652448/ Microsoft Word - EA como surgiu $>$. Acesso em: 20 de julho de 2016.

THOMAZ, Clélio Estevão; CAMARGO, Dulce Maria Pompêo de. EDUCAÇÃO AMBIENTAL NO ENSINO SUPERIOR: MÚLTIPLOS OLHARES. REMEA - Revista Eletrônica do Mestrado de Educação Ambiental, [S.I.], v. 18, abr. 2013. ISSN 1517-1256. Disponível em: <https://www.seer.furg.br/remea/article/view/3555>. Acesso em: 09 de agosto de 2016.

TOZZONI-REIS, M. F. C.; Educação Ambiental: Referências teóricas no ensino superior. Interface _ Comunic, Saúde, Educ, v.5, n.9, p.33-50, 2001. Disponível em: $\quad<$ http://repositorio.unesp.br/bitstream/handle/11449/30385/S141432832001000200003.pdf? sequence=1\&isAllowed=y>. Acesso em: 21 de julho de2016. 